\title{
An investigation and analysis of working environment pollution in a lighter manufacturer
}

\author{
Bi Wang* \\ Department of Environmental Engineering, Sichuan Vocational and Technical College, 1 Xuefu Road, \\ Suining, Sichuan Privince, 629000, China
}

\begin{abstract}
In odder to control and eliminate environmental pollution at the source and protect the health of workers, the noise and air quality of the working environment of a lighter manufacturer were investigated, sampled and tested on site by using the national standard method. The results showed that the noise of $8 \mathrm{~h}$ Leq value in ultrasonic welding post was $87.5 \mathrm{~dB}(\mathrm{~A})$, which exceeded the national occupational health standard. The noise for $8 \mathrm{~h}$ Leq value, dust and liquefied petroleum gas content of the other post were lower than that of the national occupational health standard limits. Comprehensive and effective pollution control measures are put forward
\end{abstract}

Keywords: Working environment; Pollute; Protecting health; Noise; Dust; Measures.

\section{Introduction}

Lighter is a kind of common life goods, small size, easy to use, annual consumption is huge. In the production process, noise, dust and volatile gas will be emitted, and if the value exceeds the standard, the working environment will be polluted. In order to implement the national regulations and standards on occupational health, clarify the occupational hazard factors and key control points of the enterprise, control and eliminate the pollution of the working environment from the source, protect the health of workers, and provide scientific basis for the supervision department and the daily management of the enterprise, the field investigation, sampling and detection of the pollution factors of the working environment of a lighter manufacturer were carried out.

\section{Surveyobject and method}

\subsection{Surveyobject}

During the normal production period of a lighter production enterprise in Sichuan, the concentration or intensity of pollution factors such as noise, dust, chemical poisons, etc. in the working environment produced or existing in all workshops and processes were detected.

\footnotetext{
*Corresponding author: wyb285@sina.com
} 


\subsection{On site sampling and detection methods}

According to the requirements of (GBZ / T159-2017) sampling specification for monitoring harmful substances in the air of workplace ${ }^{[1]}$, the production workshop was arranged on site. HS6288B noise spectrum analyzer (Hongsheng company) was used to detect the noise in the workshop; IFC-2 dust sampler and ES1055A/10000 electronic balance (Deant company) used to detect the dust in the workshop; Gas bag and TDP-1000C air sampler and GC7980 gas chromatograph (TianMei (China) scientific instruments Co., Ltd) were used to detect the liquefied petroleum gas, benzene, toluene and in the workshop.

\subsection{Detection index and evaluation basis}

According to the law of the people's Republic of China on the prevention and control of occupational diseases, GBZ1-2010 Hygienic Standard for the Design of Industrial Enterprises $^{[2]}$, GBZ2.1-2019 Occupational Exposure Limits for Hazardous Factors in the Workplace Part 1 Chemical Hazardous Factors ${ }^{[3],}$ and GBZ2.2-2019 Occupational Exposure Limits for Hazardous Factors in the Workplace Part $2^{[4]}$ physical Factors, the environmental pollution factors that harm the health of workers were comprehensively evaluated.

\subsection{Identification of environmental pollution factors in workplace}

\subsubsection{Production process}

AS (acrylonitrile styrene co polymer) and ABS (polyacrylonitrile butadiene styrene co polymer) are the raw materials for lighter shell manufacturing in this enterprise, which are made by injection molding after crushing and batching. The injection molding temperature is $200{ }^{\circ} \mathrm{C}$, the injection molding machine itself has heat insulation facilities, and the outer wall temperature is $30^{\circ} \mathrm{C}$. The lighter is filled with liquefied petroleum gas. The production process is as follows:

Raw material crushing $\rightarrow$ injection molding $\rightarrow$ ultrasonic welding $\rightarrow$ face valve installation $\rightarrow$ liquefied petroleum gas filling $\rightarrow$ fire test $\rightarrow$ gasket turning $\rightarrow$ pin insertion $\rightarrow$ assembly $\rightarrow$ inspection $\rightarrow$ printing $\rightarrow$ color separation $\rightarrow$ packaging $\rightarrow$ warehousing

\subsubsection{Environmental pollution factors in workplace}

Based on the analysis of the production process and raw and auxiliary materials, combined with the harm degree of each component to human body, the environmental pollution factors and their links in the workplace of the enterprise are determined as follows: noise will be produced in a series of processes such as raw material crushing, injection molding, ultrasonic welding and gas charging; other dust will be contacted in the process of raw material crushing, batching and waste recycling in the injection molding workshop; noise will be generated in the process of storage tank, and gas charging. The printing process will be exposed to chemical hazards such as liquefied petroleum gas. 


\section{Detection results and evaluation of environmental pollution factors in workplace}

\subsection{Field noise test results}

15 posts and 23 noise measurement points are selected. The measurement and calculation results are shown in Table 1. Leq. $8 \mathrm{~h}$ stands for $8 \mathrm{~h}$ equivalent continuous a sound level.

Table1. Measurement result of the Leq. $8 \mathrm{~h}$ of each relevant post.

\begin{tabular}{lccl}
\hline measurement point & $\begin{array}{c}\text { measurement result } \\
\text { Leq.8h[dB(A)] }\end{array}$ & $\begin{array}{c}\text { standard limit } \\
\text { Leq.8h[dB(A)] }\end{array}$ & result judgement \\
\hline Molding machine & 83.7 & 85.0 & qualified \\
crushing & 83.2 & 85.0 & qualified \\
ultrasonic welding & 87.5 & 85.0 & unqualified \\
face valve installation & 79.2 & 85.0 & qualified \\
LPG filling & 76.0 & 85.0 & qualified \\
inflation(full-auto) & 81.4 & 85.0 & qualified \\
inflation(semi-auto) & 75.8 & 85.0 & qualified \\
Fire test & 75.0 & 85.0 & qualified \\
gasket turning & 74.2 & 85.0 & qualified \\
pin insertion & 73.7 & 85.0 & qualified \\
assembly & 60.2 & 85.0 & qualified \\
inspection & 75.2 & 85.0 & qualified \\
printing & 68.7 & 85.0 & qualified \\
color separation & 65.2 & 85.0 & qualified \\
packaging & 64.3 & 85.0 & qualified \\
\hline
\end{tabular}

The results showed that the Leq. $8 \mathrm{~h}$ of ultrasonic welding post exceeded the standard, and the Leq. $8 \mathrm{~h}$ of noise of other posts did not exceed the occupational exposure limit

\subsection{Results of dust concentration measurement in the air on site}

The calculation results of dust concentration in air of the position exposed to dust, C-TWA and PC- TWA are shown in Table 2. The results show that the workers' exposure to dust does not exceed the occupational exposure limit of PC-TWA and the concentration of dust in short time does not exceed the limit multiple requirement.

Table 2. Results of dust concentration measurement in the air on site.

\begin{tabular}{|c|c|c|c|c|c|c|}
\hline \multirow[t]{2}{*}{ workshop } & \multirow[t]{2}{*}{ post } & \multicolumn{2}{|c|}{$\begin{array}{l}\text { measurement } \\
\text { result }\left(\mathrm{mg} / \mathrm{m}^{3}\right)\end{array}$} & \multicolumn{2}{|c|}{$\begin{array}{l}\text { Standard } \\
\operatorname{limit}\left(\mathrm{mg} / \mathrm{m}^{3}\right)\end{array}$} & \multirow{2}{*}{$\begin{array}{l}\text { Result } \\
\text { judgement }\end{array}$} \\
\hline & & C-TWA & EL & PC-TWA & ELS & \\
\hline \multirow{3}{*}{ Molding } & $\begin{array}{l}\text { raw marerial } \\
\text { crushing }\end{array}$ & $<1.0$ & 0.1 & 8 & 2 & qualified \\
\hline & batching & $<0.7$ & 0.1 & 8 & 2 & qualified \\
\hline & Waste recycling & $<0.7$ & 0.1 & 8 & 2 & qualified \\
\hline
\end{tabular}

Note: C-TWA stands $8 \mathrm{~h}$ time weighted average concentration; PC-TWA stands $8 \mathrm{~h}$ time permissible concentration-time weighted average; EL stands for limit multiple; ELS stands for max limit multiple.

\subsection{Test results of chemical harmful factors in the air}

See Table 3 for the concentration detection results and time weighted average concentration calculation results of chemical hazards in the air of workplace. 
Table 3. Concentration detection results of chemical harmful factors in the air of workplace.

\begin{tabular}{|c|c|c|c|c|c|c|}
\hline \multirow[t]{2}{*}{ post } & \multirow{2}{*}{$\begin{array}{l}\text { chemical } \\
\text { harmful } \\
\text { factor }\end{array}$} & \multicolumn{2}{|c|}{$\begin{array}{l}\text { measurement } \\
\text { result }\left(\mathrm{mg} / \mathrm{m}^{3}\right)\end{array}$} & \multicolumn{2}{|c|}{$\begin{array}{l}\text { Standard limit } \\
\left(\mathrm{mg} / \mathrm{m}^{3}\right)\end{array}$} & \multirow{2}{*}{$\begin{array}{l}\text { Result } \\
\text { judgeme } \\
\text { nt }\end{array}$} \\
\hline & & C-STEL & C-TWA & PC-STEL & PC-TWA & \\
\hline \multirow{2}{*}{\multicolumn{2}{|c|}{$\begin{array}{l}\text { inflation(full- liquefied } \\
\text { auto) petroleum gas, } \\
\text { inflation(semi liquefied } \\
\text {-auto) petroleum gas, }\end{array}$}} & $44.5-189.0$ & $<157.6$ & 1500 & 1000 & qualified \\
\hline & & $50.6-151.1$ & $<143.5$ & 1500 & 1000 & qualified \\
\hline \multirow[t]{2}{*}{$\begin{array}{l}\text { Restoration } \\
\text { tank }\end{array}$} & $\begin{array}{l}\text { liquefied } \\
\text { petroleum gas, }\end{array}$ & $<2.4$ & $<2.4$ & 1500 & 1000 & qualified \\
\hline & benzene & $<0.6$ & $<0.6$ & 10 & 6 & undetected \\
\hline \multirow[t]{2}{*}{ printing } & toluene & $<1.2$ & $<1.2$ & 100 & 50 & undetected \\
\hline & xylene & $<3.3$ & $<3.3$ & 100 & 50 & undetected \\
\hline
\end{tabular}

Note: PC-STEL stands time pemissible concentration-short term exposure limit; C-STEL stands short time exposure concentration.

The results showed that: the maximum C-TWA value of LPG in each sampling point did not exceed the requirements of PC-TWA occupational exposure limit; the short-term detection value did not exceed the requirements of PC-STEL; benzene, toluene and xylene were not detected in each sampling point.

\section{Conclusions}

It can be seen from the above that the main pollution factor of the working environment of the enterprise is the noise from the ultrasonic welding post, followed by the dust from the injection molding workshop and the liquefied petroleum gas from the inflatable post.

\section{Suggestions on pollution control measures}

The noise of ultrasonic welding post is caused by secondary friction between ultrasonic welding machine and plastic parts, which lasts for a short time but sharp. Working long in this environment is easy to cause hearing damage, and finally easy to form hearing impairment as occupational deafness, which is difficult to recover ${ }^{[5]}$. Therefore, the protective measures need to be rectified.

Although the liquefied petroleum gas concentration in the gas filling workshop is very low, there is a strange smell occasionally in the workshop; the dust concentration in crushing and waste recycling posts is also very low, but the long-term exposure to such low concentration liquefied gas and dust should also cause enough attention to the harm to human health ${ }^{[6]}$. Therefore, measures must be taken to control and eliminate pollution.

\subsection{Control noise and dust pollution from the source}

\subsubsection{Take measures to isolate noise}

Set up sound insulation room to isolate ultrasonic welding machine, or customize the sound insulation cover to close the welding machine, so as to reduce noise and improve the working environment of the whole workshop ${ }^{[7]}$.

\subsubsection{Take measures to reduce dust}

Increase the air tightness of the pulverizer, reduce the dust escape, install the dust hood and 
timely carry out the dust collection cover, clean up to ensure dust removal efficiency ${ }^{[8]}$.

\subsection{Strengthen protective measures for workers}

\subsubsection{Wear masks and earplugs}

Establish the supervision and management system for the distribution of personal protective articles, especially to urge ultrasonic welding workers to wear noise proof earplugs or earmuffs correctly (SNR is 17-34 dB), urge the workers in injection molding workshop to wear dust masks of kn95 or above; and try to reduce the actual contact time of noise ${ }^{[9]}$.

\subsubsection{Improve the overall ventilation of workshop}

Add exhaust and supply equipment with enough power and air volume to strengthen the whole room ventilation in the workshop, reduce the accumulation of liquefied petroleum gas and improve the air quality of the workshop

\subsection{Strengthen management measures}

Do a good job in technical training of workshop workers and improve their awareness of environmental pollution prevention and control

- Set warning signs and warning instructions in post of contacting dust, noise and liquefied petroleum gas.

- Do well in the occupational health training of workshop workers, popularize occupational health knowledge, urge workers to abide by laws, regulations and operation rules of occupational disease prevention and control, and improve workers' awareness of protection;

- Carry out regular occupational health examination for workshop workers, and establish health files for workshop staff

- Regularly do well in the inspection of dust, noise and liquefied petroleum gas in the workshop. If any of the above is found, reasons shall be found in time and corresponding measures shall be taken to make it conform to the national occupational health standards to ensure the health and safety of the workers on the post.

\section{References}

1. GBZ/T159-2017 sampling code for monitoring harmful substances in the air in workplace

2. GBZ1-2010 hygienic standard for industrial enterprise design

3. GBZ2.1-2019 occupational exposure limit of hazardous factors in Workplace Part 1: chemical hazardous factors

4. GBZ2.2-2019 occupational exposure limit of hazardous factors in Workplace Part 2 physical factors

5. Zihuang Xie, Weihong Chen, Occup Health \& Emerg Rescue 35, 6(2017)

6. Weiwei Zhou, Yu Rongtie, Occup Health \& Emerg Rescue,38,603(2020)

7. Fang Ji, Xiaowen Ding, J. Envir. Occup . Medic. 37,1194(2020)

8. Shoufeng Sun, guopo Zhao ,Modern Occupational Safety, 21,96(2021)

9. Longfei Shen, Chemical Enterprise Management, 34,47 (2020) 